\title{
Torção de Útero Não-Grávido
}

\author{
Torsion of the Non-Pregnant Uterus
}

Lúcia Alves da Silva Lara, Ângelo Gualberto de Macêdo,

Antônio Carlos de Faria, Adir Batista,

Renato Antônio Soares Lima, Maria Aparecida Silveira Sucena

\begin{abstract}
RESUMO
A torção uterina é uma patologia bastante rara, de diagnóstico dificil e está geralmente associada ao aumento do volume uterino em combinação com outras alterações dos órgão pélvicos. Este trabalho relata o caso de uma mulher idosa, desnutrida, com quadro de abdome agudo e diagnóstico intra-operatório de miomatose e torção de $360^{\circ}$ para a direita do útero que apresentava sinais de grave isquemia.
\end{abstract}

PALAVRAS-CHAVE: Mioma. Abdome agudo. Laparotomia.

\section{Introdução}

Torção uterina é definida como sendo uma rotação de mais de $45^{\circ}$ do útero em torno do seu eixo axial $^{3,4}$. Sua patogenia não está ainda bem esclarecida. Alguns autores atribuem a sua ocorrência aos processos que implicam aumento ou diminuição do volume do útero, secundários aos processos degenerativos dos miomas uterinos; também as pulsações dos vasos adjacentes ao órgão, as malformações uterinas, os movimentos de rotação do corpo em decúbito e, nas gestantes, a apresentação fetal anormal tomariam parte neste evento raro $^{2,3}$.

Santa Casa de Misericórdia de Piumhi (MG)

Correspondência:

Lúcia Alves da Silva Lara

Rua Tereza Hostalácio, 40 - Centro.

37925-000 - Piumhi - MG.

Telefax: (037) 371.2123.
A torção de útero não-grávido é mais comum nos animais do que nos humanos. Incide mais em mulheres acima de quarenta anos, sendo extremamente rara na infância e adolescência ${ }^{2}$. A grande maioria dos casos relatados na literatura refere-se a úteros gravídicos, sendo poucos os casos associados a miomas ou malformações uterinas. Ocorre no nivel do colo uterino ${ }^{2}$ e em mais de $60 \%$ dos casos no sentido horário ${ }^{1,2,4}$. É causa de graus variáveis de isquemia, podendo esta levar até a necrose. A literatura, porém mostra casos de torção de útero grávido diagnosticados durante a cesariana com fetos vivos e a termo ${ }^{2,3,4,7,8}$.

O quadro clínico é inespecífico. Manifestase, nos casos agudos, por vômitos, dor intensa no hipogástrico, onde se palpa massa dolorosa, e debilidade do estado geral. Quando associada à gravidez, manifesta-se por dor, trabalho de parto prematuro e às vezes descesso fetal, mas o quadro pode permanecer estável e a gestação chegar ao termo $o^{1,3,4,6,8}$. 
O diagnóstico é feito quase sempre durante o ato cirúrgico. A ultra-sonografia é inespecífica. Nicholson et al. ${ }^{5}$ relataram um caso de torção de útero grávido diagnosticado por meio da ressonância magnética, que mostrava a cúpula vaginal em formato de $\mathrm{X}$.

O tratamento é cirúrgico. É necessário considerar a idade e a paridade da paciente e o grau de comprometimento do órgão para definir a extensão da cirurgia.

\section{Descrição do Caso Clínico}

HMJ, sexo feminino, 70 anos, negra; altura de 1,51 m; peso: $43 \mathrm{~kg}$; com índice de massa corporal de 18,8. Apresentava queixa de dor forte e contínua no baixo ventre e vômitos. Ao exame, apresentava-se desnutrida, com facies de sofrimento e mucosas hipocoradas. Pressão arterial de $150 / 80 \mathrm{mmHg}$, pulso $76 \mathrm{bpm}$, temperatura de $37^{\circ} \mathrm{C}$. No abdome, palpava-se massa de consistência firme, com limites precisos, móvel e dolorosa, atingindo a cicatriz umbilical.

Relatava que há dois anos sentia esporadicamente dores tipo cólica no baixo ventre, às vezes acompanhadas de vômitos. As dores cediam espontaneamente.

A ultra-sonografia evidenciava massa sólida com áreas de calcificações, medindo $113 \mathrm{~mm} \times 111 \mathrm{~mm}$ em suas maiores dimensões. Não foi observado líquido livre na cavidade abdominal (Figura 1). Suspeitou-se de tumor ovariano ou miomatose uterina. O hemograma mostrava $\mathrm{Hb}=11,5 \mathrm{~g} / \mathrm{dl}$ e global de leucócitos de 5.200/ $\mathrm{mm}^{3}$ sem desvio à esquerda. $\mathrm{O}$ exame de sedimento urinário era normal. Os niveis de proteínas totais eram $6,8 \mathrm{~g} / \mathrm{dl}$, com albumina de $2,3 \mathrm{~g} / \mathrm{dl}$ e globulinas de 4,5 g/dl e relação A/G 0,51.

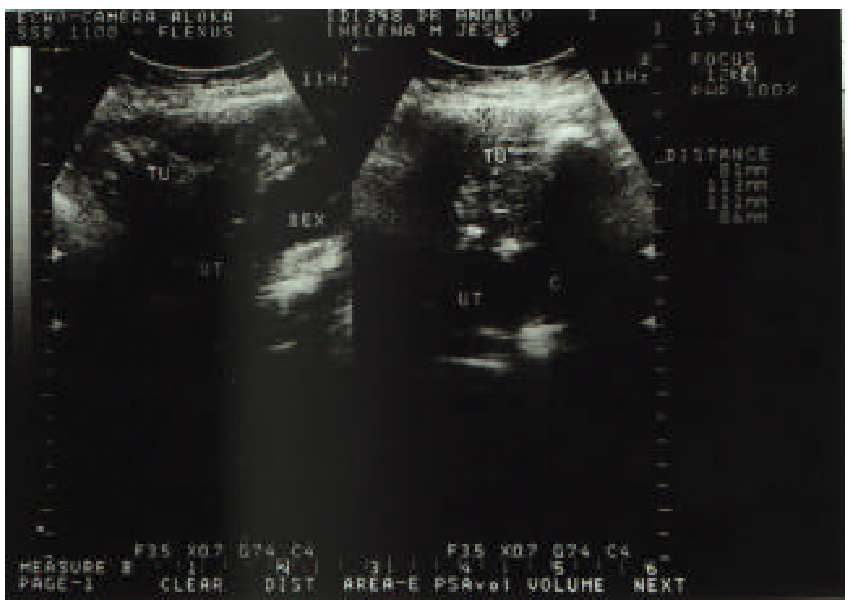

FIGURA 1 - Massa pélvica heterogênea com áreas hiperecogênicas sugestivas de calcificações (útero)
A paciente foi internada e medicada com analgésicos e soroterapia. Três dias após, como o quadro clínico houvesse se agravado, optou-se pela intervenção cirúrgica. Havia moderada quantidade de líquido vinhoso na cavidade abdominal. O útero atingia a cicatriz umbilical, tinha coloração vinhosa e continha vários nódulos na sua superficie, com focos de necrose. O útero e a cúpula vaginal estavam torcidos em uma volta completa $\left(360^{\circ}\right)$. Os ovários e trompas uterinas também mostravam sinais de grave isquemia. Foi realizada histerectomia corporal com anexectomia.

A paciente recebeu alta quatro dias após a cirurgia, em boas condições. Três dias após, retornou ao hospital com quadro de febre (temperatura axilar de $38,5^{\circ} \mathrm{C}$ ), dor abdominal difusa, náuseas, vômitos e diarréia. O hemograma evidenciava hemoglobina de $11 \mathrm{~g} / \mathrm{dl}$ e contagem global de leucócitos de $18400 / \mathrm{mm}^{3}$, com $5 \%$ de bastonetes. O diagnóstico clínico foi de gastroenterite. Foi tratada com antibiótico, soroterapia e antitérmicos. Recebeu alta cinco dias após, em boas condições.

O exame anátomo-patológico evidenciou corpo uterino medindo $16,0 \times 15,0 \times 11,0 \mathrm{~cm}$. A superficie serosa era acastanhada. Aos cortes o miométrio era vinhoso e identificavam-se múltiplos nódulos intramurais de tamanhos variados, que mediam entre $0,8 \mathrm{~cm}$ e $10 \mathrm{~cm}$. A cavidade endometrial encontrava-se alargada, com superficie lisa e brilhante. Os ovários mediam $5,0 \times 3,0 \times 2,0 \mathrm{~cm}$ à esquerda e 4,0 x 3,0 x 2,0 cm à direita. Apresentavam consistência friável e coloração vinhosa. As trompas mediam $6,0 \times 1,0 \mathrm{~cm}$ cada, com superficie serosa acastanhada e luz virtual. O diagnóstico foi de leiomiomas múltiplos do corpo uterino, alguns calcificados; ovários e trompas com hemorragia intersticial difusa. Compativel com infarto hemorrágico (Figura 2).

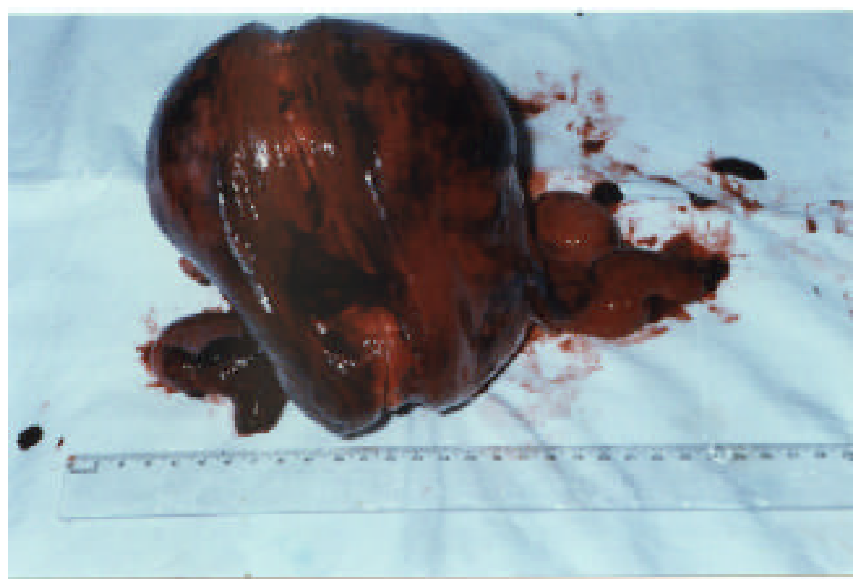

FIGURA 2 - Útero aumentado de volume com colaboração vinhosa e áreas de necrose. 
Dois meses após a cirurgia, a paciente referia estar se sentindo bem e apresentava bom estado geral, com peso de $47 \mathrm{~kg}$.

\section{Discussão}

A importância desse caso resulta da coexistência de duas patologias raras. A primeira é a persistência de mioma de grandes dimensões em mulher idosa, uma vez que, após a menopausa, esses tumores tendem naturalmente a diminuir de tamanho; a segunda é a torção uterina, que se mostra ainda mais rara e com mecanismo ainda não elucidado.

Por se tratar de paciente idosa e desnutrida, pensamos que a fragilidade dos tecidos de sustentação e contenção do útero, associada à presença de grande massa tumoral, tenha também contribuído para o mecanismo da torção. Segundo Bolognese et al. ${ }^{2}$, o colo uterino alongado e atrófico após a menopausa funcionaria também como pedículo, facilitando a rotação.

Não foi possivel determinar a incidência desta patologia na população geral, uma vez que quase todos os casos publicados referem-se à torção de útero gravídico. São poucos os casos relatados na literatura que descrevem a torção ocorrida em útero miomatoso não-grávido² .

É importante salientar as dificuldades para se chegar ao diagnóstico pré-operatório. O processo pode ser insidioso, pois os fenômenos isquêmicos provocados pelo comprometimento das artérias uterinas são temporariamente compensados pela circulação colateral proveniente principalmente das artérias ovarianas $^{2}$.

A proposta cirúrgica de preservação do órgão consiste no encurtamento e fixação do ligamento redondo no corpo uterino ${ }^{6}$, ficando a histerectomia restrita aos casos de grande comprometimento do órgão e, eventualmente, às mulheres menopausadas.

\section{SUMMARY}

Uterine torsion is an unusual pathology of difficult diagnosis and it is generally associated with an enlargement of uterine volume combined with other alterations of the pelvic organs. This report presents a case of a malnourished elderly woman with acute abdomen and intraoperative diagnosis of myoma and uterine torsion of 360 degrees to the right. The uterus showed signs of severe ischemia.

KEY WORDS: Myoma. Laparotomy.

\section{Referências}

1. Attapattu. JA, Prussia PR, Menon S. Torsion of a non-pregnant fibromyomatous uterus. Int $\mathrm{J}$ Gynecol Obstet 1994; 45: 163-4.

2. Bolognese RJ, Weber LL, Zachary TV Jr. Torsion ot the nongravid uterus. JAMA 1967; 199: 157.

3. Carbonne B, Cabrol D, Viltart JP, Papiernik E. Torsion of the pregnant uterus. Gynecol Obstet Biol Reprod 1994; 23: 717-8.

4. Jensen JG. Uterine torsion in pregnancy. [Review] Acta Obstet Gynecol Scand. 1992; 71: 260-5

5. Nicholson WK, Coulson CC, Mecoy MC, Semelka RC. Pelvic magnetic resonance imaging in the evaluation of uterine torsion. Obstet Gynecol 1995; 85: 888-90.

6. Pelose MA 3rd, Pelose MA. Managing extreme uterine torsion at term. A case report. Reprod Med. 1998; 43: 153-7.

7. Shneider ML. Secondary torsion of the uterus caused by a big leiomyoma. Geburtshilfe Frauenheilkd 1980; 40: 329-31.

8. Torbjorn P, Tore JM. Asymptomatic torsion of the pregnant uterus. Acta Fertil. 1992;23:185-6. 